Purdue University

Purdue e-Pubs

CTRC Research Publications

Cooling Technologies Research Center

3-1-2007

\title{
Flow Boiling Heat Transfer to a Dielectric Coolant in a Microchannel Heat Sink
}

T. Chen

S V. Garimella

Purdue University, sureshg@purdue.edu

Follow this and additional works at: http://docs.lib.purdue.edu/coolingpubs

Chen, T. and Garimella, S V., "Flow Boiling Heat Transfer to a Dielectric Coolant in a Microchannel Heat Sink" (2007). CTRC

Research Publications. Paper 60.

http://dx.doi.org/10.1109/TCAPT.2007.892063

This document has been made available through Purdue e-Pubs, a service of the Purdue University Libraries. Please contact epubs@purdue.edu for additional information. 


\title{
Flow Boiling Heat Transfer to a Dielectric Coolant in a Microchannel Heat Sink
}

\author{
Tailian Chen and Suresh V. Garimella* \\ Cooling Technologies Research Center \\ School of Mechanical Engineering \\ Purdue University \\ West Lafayette, Indiana 47907-2088 USA
}

\begin{abstract}
This paper presents an experimental study of flow boiling heat transfer in a microchannel heat sink. The dielectric fluid Fluorinert FC-77 is used as the boiling liquid after it is fully degassed. The experiments were performed at three flow rates ranging from 30 to $50 \mathrm{ml} / \mathrm{min}$. The heat transfer coefficients, as well as the critical heat flux, were found to increase with flow rate. Wall temperature measurements at three locations (near the inlet, near the exit, and in the middle of heat sink) reveal that wall dryout first occurs near the exit of the microchannels. The ratio of heat transfer rate under critical heat flux conditions to the limiting evaporation rate was found to decrease with increasing flow rate, asymptotically approaching unity. Predictions from a number of correlations for nucleate boiling heat transfer in the literature are compared against the experimental results to identify those that provide a good match. The results of this work provide guidelines for the thermal design of microchannel heat sinks in two-phase flow.
\end{abstract}

INDEX TERMS - Flow boiling heat transfer; microchannel heat sink; critical heat flux; electronics cooling

\section{NOMENCLATURE}
A Microchannel heat sink base area $\left(\mathrm{cm}^{2}\right)$
Bo $\quad$ Boiling number, $q^{\prime \prime} / G h_{f g}$
$C_{2} \quad$ Constant in equation (14)
Co Convective number, $\left(\rho_{v} / \rho_{l}\right)^{0.5}((1-x) / x)^{0.8}$
$C_{p} \quad$ Specific heat $(\mathrm{J} / \mathrm{kg}-\mathrm{K})$
$C_{\text {sf }} \quad$ Constant in equation (13)
$d \quad$ Distance of themocouples from the bottom of microchannels ( $\mathrm{mm}$ )
$D_{h} \quad$ Hydraulic diameter ( $\left.\mathrm{mm}\right)$

\footnotetext{
Author to whom correspondence should be addressed: (765) 494 5621, sureshg@ purdue.edu
} 


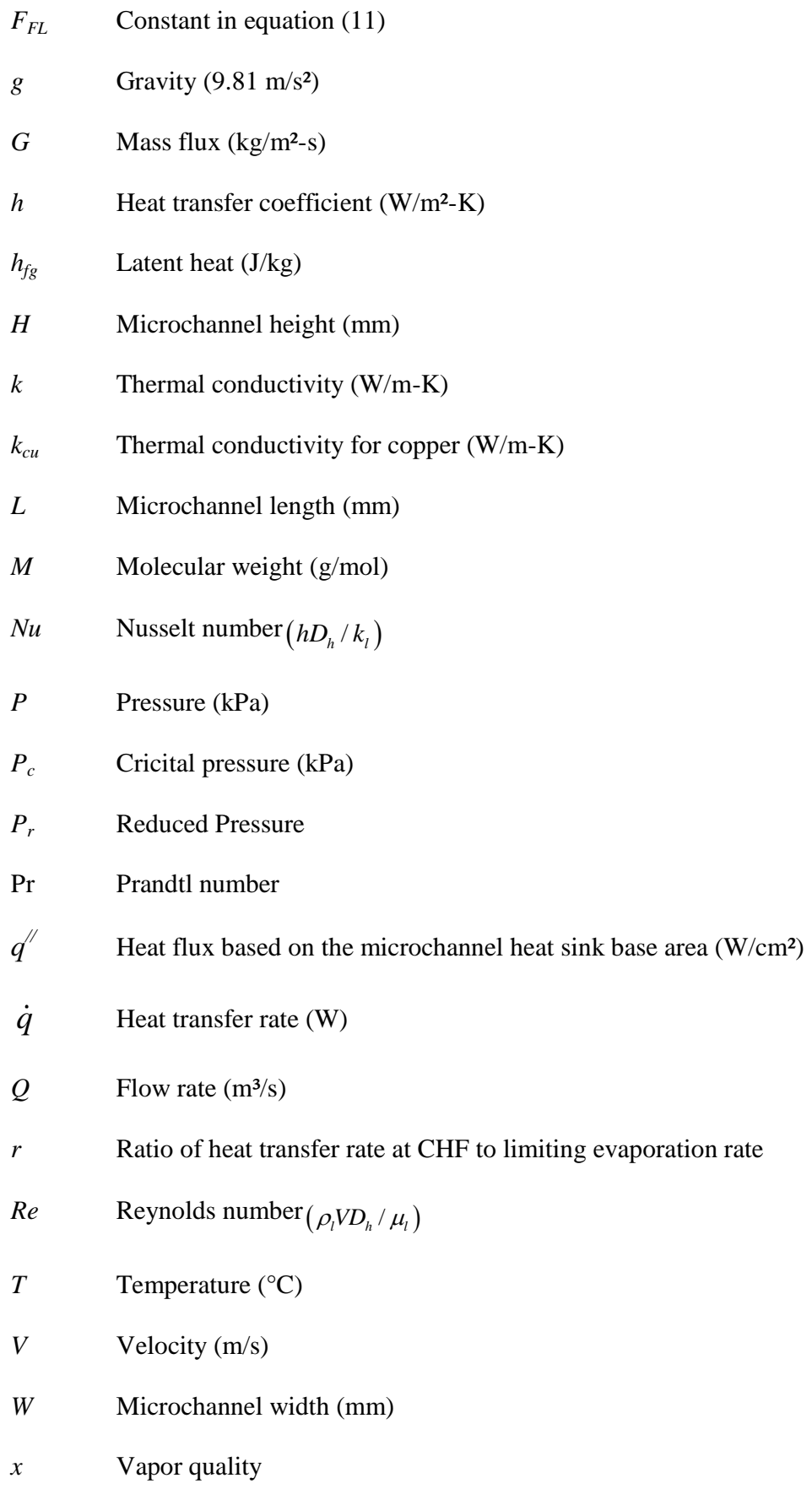




$\begin{array}{ll}\text { Subscript } & \\ \text { CHF } & \text { Critical heat flux } \\ \text { in } & \text { Microchannel inlet } \\ l & \text { Liquid } \\ \text { loss } & \text { Heat loss } \\ \text { NBD } & \text { Nucleate boiling dominant } \\ \text { out } & \text { Microchannel outlet } \\ \text { input } & \text { Heat input } \\ \text { sat } & \text { Saturation } \\ s p & \text { Single phase flow } \\ \text { TC } & \text { Thermocouple } \\ t p & \text { Two-phase flow } \\ v & \text { Vapor } \\ w & \text { Channel wall }\end{array}$

\section{INTRODUCTION}

The high heat transfer rates achievable with flow boiling in microchannels make it an attractive option for thermal management in high-heat-flux devices. A number of past studies have shown that the boiling heat transfer behavior in microchannels is different from that in conventional (larger-sized) channels. In a study of flow boiling in single channels with hydraulic diameter ranging from 1.39 to $3.39 \mathrm{~mm}$, Kew and Cornwell [1] found that boiling heat transfer in these tubes could be better predicted by nucleate boiling correlations; predictions from established flow boiling correlations for larger channels proved to be inadequate. They suggested that when the channel hydraulic diameter $D_{\mathrm{h}}$ is smaller than $\left.2 \sqrt{\sigma /\left[g\left(\rho_{l}-\rho_{v}\right)\right.}\right]$, a channel size effect on boiling heat transfer becomes evident. Tran et al. [2] studied boiling heat transfer with refrigerant R-12 in circular and rectangular channels of hydraulic diameter 2.46 mm, and found two distinct boiling regimes: a convective boiling-dominant regime at lower wall superheats, and a nucleate boiling-dominant regime at higher wall superheats. The heat transfer rate in the latter was found to be well-predicted by the nucleate boiling correlation of Stephan and Abdelsalam [3]. Mertz et al. [4] investigated flow boiling of water and R141b in multiple 
channels, each $30 \mathrm{~cm}$ long and of hydraulic diameter ranging from 1 to $4.5 \mathrm{~mm}$. The measured heat transfer coefficients for water were found to decrease with increasing heat flux over the range from 20 to $200 \mathrm{~kW} / \mathrm{m}^{2}$. A recent study of flow boiling of water in a microchannel heat sink [5] showed that heat transfer coefficients were much lower than would be predicted by established correlations for conventional flow boiling; they attributed this difference to the presence of laminar flow with its lower associated heat transfer coefficient compared to turbulent flow, an abrupt transition to slug flow, hydrodynamic instability, and a large number of liquid drops being entrained into the annular flow.

In applications involving microchannel flow boiling, it is important to understand the critical heat flux (CHF). Although CHF has been extensively studied for flow boiling in large channels, as summarized by Hall and Mudawar [6], CHF data for boiling heat transfer in microchannels are still scarce. A study of CHF for water in tubes of diameters of 0.3 to $2.7 \mathrm{~mm}$ was conducted by Vandervort et al. [7] under the following conditions: mass fluxes of 5000 to 40000 $\mathrm{kg} / \mathrm{m}^{2}$-s, exit subcoolings of 40 to $135^{\circ} \mathrm{C}$, length-to-diameter ratios of 2 to 50 , and exit pressure of 0.2 to $2.2 \mathrm{MPa}$. The values for CHF were measured to be in the range of 20 to $80 \mathrm{MW} / \mathrm{m}^{2}$, and increased with an increase in mass flux and subcooling, but decreased with increasing channel diameter. CHF was also found to be weakly dependent on exit pressure and tube length-to-diameter ratio. Dissolved air was found to have no effect on CHF. Lazarek and Black [8] measured CHF and critical quality (vapor quality in the tube cross-section where CHF occurs) of R113 in a vertical tube of diameter $3.1 \mathrm{~mm}$, and found that CHF increased with mass flux. They also found that critical quality was reduced at reduced pressure. The following correlation for critical quality accounting for inlet subcooling was proposed:

$$
x_{C H F}=1-6.075 \times 10^{-3} G D_{h}^{0.25}\left(\frac{D_{h}}{L}\right)^{0.59}\left[1+3.11\left(\frac{\Delta h_{i n}}{h_{f g}}\right)\right],
$$

in which $\Delta \mathrm{h}_{\text {in }}$ is the enthalpy difference from the saturation state of the liquid at the inlet. The boiling heat transfer coefficient was found to be independent of local vapor quality, which led to the suggestion that nucleate boiling heat transfer dominated the flow boiling contribution. In a study of flow boiling of water in a $2.98 \mathrm{~mm}$ diameter horizontal tube of length $0.91 \mathrm{~m}, \mathrm{Yu}$ et al. [9] found that the critical heat flux occurred at an exit quality in the range from 0.5 to 1.0 , and the exit quality decreased with decreasing mass flux, which they claimed was in disagreement with results found in larger tubes [10]. Bowers and Mudawar [11] studied the effects of inlet subcooling (from 10 to $30 \mathrm{~K}$ ) and flow rate (from 19 to $95 \mathrm{ml} / \mathrm{min}$ ) on CHF in the flow boiling of R-113 in mini- and micro-channel heat sinks. They observed that CHF was independent of subcooling and increased linearly with flow rate. 
The present work aims to characterize the flow boiling heat transfer of the dielectric liquid FC-77 in a microchannel heat sink for three flow rates ranging from 30 to $50 \mathrm{ml} / \mathrm{min}$, with CHF identified at each flow rate by monitoring the change in wall temperature with incremental changes in heat flux.

\section{EXPERIMENTS}

\section{Test Loop}

The experimental setup and procedures used in this work are similar to those reported in Chen and Garimella [12]. A schematic diagram of the test loop is shown in Fig. 1. A magnetically coupled gear pump drives the coolant through the loop. Tests were conducted at three flow rates: 30, 40, and $50 \mathrm{ml} / \mathrm{min}$. A precision low-flow-rate flow meter was used to monitor the flow rate, while a DC power supply was used to provide the required heat input to the microchannel

heat sink. The temperatures, flow rate, and power supply were monitored with a data acquisition system. A preheater installed upstream of the test section controls the degree of inlet subcooling, which is maintained at $17 \pm 0.5^{\circ} \mathrm{C}$ for this work. During each test run, the inlet temperature measured in the inlet manifold increases by 1 to $2^{\circ} \mathrm{C}$.

A perfluorinated dielectric fluid, FC-77, from 3M is used as the working fluid in a fully degassed state. This liquid has a boiling point of $97^{\circ} \mathrm{C}$ at atmospheric pressure and a very large air solubility ( $41 \%$ by volume) under ambient conditions which has a significant effect on boiling heat transfer behavior as established in Chen and Garimella [12]. The major component of the degassing apparatus, as shown in Fig. 2, is an expandable container which is used as the liquid reservoir to facilitate the degassing process while maintaining the desired system operating conditions (pressure and temperature). The reservoir was tested to be leak-free, and then filled with liquid FC-77. Degassing was performed by repeatedly evacuating the reservoir of air (and FC-77 vapor) from the top using a vacuum pump until the pressure in the reservoir remains at its maximum vacuum level and is unchanged with time. The oxygen content of degassed liquid was measured to be less than $3 \mathrm{ppm}$, which is equivalent to $0.000215 \mathrm{moles} / \mathrm{mole}$ of air content ( $0.022 \%$ by volume). Therefore it is considered a satisfactory level of degassing. As shown in Fig. 1, the test loop has a second degassing port. This port is used to evacuate air from the test loop prior to charging it with liquid. When the liquid in the test loop and reservoir is degassed, the constraint mechanism on the reservoir is adjusted to allow the bellows to contract such that the pressure in the test section is maintained at atmospheric pressure. Details of the degassing procedure are available in Chen and Garimella [12]. 


\section{$\underline{\text { Microchannel Heat Sink }}$}

The test piece is a microchannel heat sink machined from oxygen-free copper. As shown in Fig. 3a, the heat sink has dimensions of $25.4 \mathrm{~mm} \times 25.4 \mathrm{~mm} \times 7 \mathrm{~mm}$. The heat sink contains 10 microchannels, each of width $504 \mu \mathrm{m}$ and depth $2.5 \mathrm{~mm}$ (for a hydraulic diameter of $839 \mu \mathrm{m}$ ), extending the length of the heat sink. One thermocouple is inserted at each of three locations $\left(\mathrm{TC}_{1}, \mathrm{TC}_{2}, \mathrm{TC}_{3}\right)$ in the lengthwise direction underneath the microchannels along the center of the test section, as shown in Fig. 3a. The thermocouples are located at a distance of $3.1 \mathrm{~mm}$ below the bottom of microchannels, with $\mathrm{TC}_{1}$ being $2 \mathrm{~mm}$ from the inlet in the flow direction, $\mathrm{TC}_{2}$ in the middle, and $\mathrm{TC}_{3} 2 \mathrm{~mm}$ prior to the exit. A $25 \mathrm{~mm}$ square resistance heater, custom-fabricated in-house with serpentine nichrome wire, is attached to the bottom of the copper heat sink to provide heat input to the microchannels. The resistance of the nichrome wire heater is measured to be $16.5 \Omega$ at room temperature. In view of the weak temperature-dependence of resistance for nichrome $(0.0004 \Omega / \Omega-\mathrm{K})$, the change in heater resistance for the temperature range encountered in this work was only $0.04 \Omega / \Omega$, so that an assumption of temperature-independent resistance was justified.

The copper heat sink is housed in the test section as shown in Fig. $3 \mathrm{~b}$; all experiments were conducted with the microchannel heat sink oriented horizontally. The test section consists of a main body, top and bottom covers, and a heat sink support cube. The main body and support cube are made of G-10 fiberglass which has a very low thermal conductivity $(0.22 \mathrm{~W} / \mathrm{m}-\mathrm{K})$ so that the heat sink is well insulated. The heat sink is press-fit into the housing, with any gaps around the heat sink sealed with a high-temperature epoxy of low thermal conductivity $(\sim 0.60 \mathrm{~W} / \mathrm{m}-\mathrm{K})$. The main body contains inlet and outlet plenums to distribute the flow into the microchannels. Two pressure taps and two thermocouples located in the inlet and outlet manifolds measure the pressure drop and temperature rise across the microchannel test section, respectively. Pressure drop was measured using a differential pressure transducer, which was zero-adjusted prior to use. The heat sink support cube is supported by four springs to eliminate gaps between the heat sink and the top cover. A groove on one side of the support cube allows access for the electrical leads of the nichrome heater and thermocouple wires.

\section{$\underline{\text { Data Analysis }}$}

The measured temperatures at the three locations $\left(\mathrm{TC}_{1}, \mathrm{TC}_{2}, \mathrm{TC}_{3}\right)$ underneath the microchannels shown in Fig. 3a were first corrected to obtain the three corresponding wall temperatures, as:

$$
T_{w i}=T_{T C, i}-\frac{\dot{q} d}{A k_{c u}} \quad i=1,2,3
$$


The average wall temperature was calculated by averaging these three wall temperatures. Under the constant heat flux boundary condition imposed on the microchannel heat sink, the log mean temperature difference (LMTD) represents the wall-to-fluid temperature difference:

$$
\Delta T_{\text {LMTD }}=\frac{T_{\text {out }}-T_{\text {in }}}{\ln \left(\frac{T_{w}-T_{\text {in }}}{T_{w}-T_{\text {out }}}\right)}
$$

During single-phase flow prior to the inception of boiling in the microchannels, the sensible heat gain by the liquid is given by

$$
\dot{q}_{s p}=\rho Q C_{p}\left(T_{\text {out }}-T_{\text {in }}\right)
$$

and the difference between the measured input power and the sensible heat gain by the liquid is denoted as the heat loss due to conduction losses through the housing and insulation:

$$
\dot{q}_{\text {Loss }}\left(T_{w}\right)=\dot{q}_{\text {input }}-\dot{q}_{s p}
$$

The heat loss was found to increase linearly with wall temperature, according to:

$$
\dot{q}_{\text {Loss }}\left(T_{w}\right)=0.2239 \times T_{w}-12.46
$$

in which the constants are applicable only to the test section considered. As would be expected, the variation of wall temperature with input heat flux decreased greatly once boiling was initiated. However, the heat losses in the two-phase regime are still dominated by conduction through the housing and insulation, and can be calculated using equation (6). The energy gained by the liquid during the boiling process can thus be determined as:

$$
\dot{q}_{t p}=\dot{q}_{\text {input }}-\dot{q}_{\text {Loss }}\left(T_{w}\right)
$$

The heat transfer coefficients for single- and two-phase flow are thus readily calculated, respectively, as:

$$
\begin{gathered}
h_{s p}=\frac{\dot{q}_{s p}}{A \cdot \Delta T_{L M T D}} \\
h_{t p}=\frac{\dot{q}_{t p}}{A \cdot\left(T_{w}-T_{s a t}\right)}
\end{gathered}
$$

\section{Uncertainty Analysis}

The uncertainties (at a confidence level of 95\%) in the reported measurements are determined as follows. The flow rate has an uncertainty of $1 \%$, mainly arising from the reading accuracy of the flow meter. The uncertainty in temperature $\left( \pm 0.5^{\circ} \mathrm{C}\right)$ and flow rate measurements lead to an uncertainty in the single-phase heat transfer rate computed 
using equation (4) of 7.5 to $40.4 \%$ following the approach of Kline and McClintock [13]; the larger uncertainties occurred at the lower wall temperatures. For two-phase flow, the heat transfer rate obtained by equation (7) has two sources of uncertainty: input power, $\dot{\mathrm{q}}_{\text {in }}$, and heat loss, $\dot{q}_{\text {Loss }}$; the total uncertainty for two-phase heat transfer rate was determined to be in the range of $6.1 \%$ to $7.5 \%$. Neglecting the uncertainty in determination of the base area of the heat sink, the uncertainties in heat transfer coefficient are estimated to range from $6.3 \%$ to $26.1 \%$ for single-phase flow and $4.5 \%$ to $6.3 \%$ for two-phase flow.

\section{Single-Phase Heat Transfer Measurements}

Nusselt numbers for single phase heat transfer obtained at the three flow rates are presented in Fig. 4. Since the flow is laminar at all three flow rates ( $\operatorname{Re}=47,63,79$, respectively), Nusselt numbers remain relatively constant. The spread in the results around the expected value is due to the larger uncertainties in heat loss determination at the lower heat inputs. For single phase laminar flow in a rectangular channel under a constant heat flux boundary condition, the Nusselt number is given by the following equation [14],

$$
N u=8.235\left(1-2.0421 \beta+3.0853 \beta^{2}-2.4765 \beta^{3}+1.0578 \beta^{4}-0.1861 \beta^{5}\right),
$$

and is calculated to be 5.74 for the channel aspect ratio of $\beta=0.2$ used in this study. This predicted Nusselt number is also included in Fig. 4, illustrating a reasonable agreement with measured Nusselt numbers for single-phase flow.

\section{RESULTS AND DISCUSSION}

\section{$\underline{\text { Heat Transfer }}$}

As listed in Table 1, the heat fluxes and wall temperatures at which bubbles were first observed to appear in microchannels depend on the flow rate; the higher the flow rate, the higher is the heat flux and the wall temperature needed for bubble nucleation. It is noted that the wall temperatures for bubble incipience reported here are obtained for a liquid subcooling of $17 \mathrm{~K}$, and are slightly lower (by 1 to $2 \mathrm{~K}$ ) compared with the greater subcooling level in the authors' previous work [12] of $54 \mathrm{~K}$.

Table 1. Approximate heat fluxes and wall temperatures for bubble incipience.

\begin{tabular}{c|l|l|l}
\hline Flow rate $(\mathrm{ml} / \mathrm{min})$ & 30 & 40 & 50 \\
\hline Heat flux $\left(\mathrm{W} / \mathrm{cm}^{2}\right)$ & 0.90 & 1.21 & 1.61 \\
\hline Wall temperature $\left({ }^{\circ} \mathrm{C}\right)$ & 100 & 101.8 & 103.2 \\
\hline
\end{tabular}


The change in wall temperature as a function of heat flux is shown in Fig. 5. Visual observation revealed that bubbles first start to appear in the microchannels at either lateral end of the heat sink and subsequently appear in all microchannels at higher heat fluxes. Since the temperatures in Fig. 5 represent the average over all the microchannels, the transition from single phase to two-phase regimes is observed in the figure when boiling has been initiated in most of the microchannels. Thus, the regime demarcation in Fig. 5 occurs at temperatures and wall heat fluxes which are approximately $3{ }^{\circ} \mathrm{C}$ and $0.5 \mathrm{~W} / \mathrm{cm}^{2}$ higher, respectively, than the conditions for bubble incipience in the microchannels at the lateral ends of the heat sink (given in Table 1).

After the boiling process is well established in the microchannels, the wall temperature remains relatively constant, and is approximately the same for the three flow rates at low heat fluxes (from 3 to $8 \mathrm{~W} / \mathrm{cm}^{2}$ ). As heat flux is further increased, the wall temperature exhibits a weak dependence on heat flux and deviates somewhat for the different flow rates. This weak dependence of wall temperature on heat flux appears to be due to flow oscillations, the magnitude of which increases with heat flux [12]. The flow oscillations cause vapor bubbles to reside in the channels for a longer period of time, thus reducing the replenishment with colder liquid and the effectiveness of heat transfer. An oscillation in the flow was visually observed in the form of a flow reversal: bubbles were seen to be ejected from the channel inlet into the upstream plenum and were then immediately swept back into the channel. A back-and-forth oscillation of bubbles nucleating from the microchannel wall before detaching from their nucleation sites was also observed.

Also marked on Fig. 5 are the CHF values for the three flow rates (30, 40, and $50 \mathrm{ml} / \mathrm{min}$ ) identified by monitoring the wall temperature variation at each heat flux; numerical values are listed in Table 2. Prior to CHF, the wall temperature remains constant over time for a given heat flux; just beyond CHF the wall temperature is seen to rise rapidly for any further increases in heat flux as illustrated in Fig. 6 for the flow rate of $50 \mathrm{ml} / \mathrm{min}$. At this point, the power supply is turned off to prevent damage to the test section. Fig. 6 shows that both the magnitude of heat flux and wall temperature at which CHF occurs increase with increasing flow rate. Further discussion on CHF is provided later in this paper.

Table 2. Critical heat fluxes at three flow rates.

\begin{tabular}{c|c|c|c}
\hline Flow rate $(\mathrm{ml} / \mathrm{min})$ & 30 & 40 & 50 \\
\hline $\mathrm{CHF}\left(\mathrm{W} / \mathrm{cm}^{2}\right)$ & 13.4 & 18.1 & 21.3 \\
\hline
\end{tabular}

Readings from the three wall thermocouples $\mathrm{TC}_{1}, \mathrm{TC}_{2}, \mathrm{TC}_{3}$ reveal a considerable increase in temperature along the flow direction at the higher heat fluxes, as shown in Fig. 7 for the flow rate of $30 \mathrm{ml} / \mathrm{min}$. This implies that at high heat 
fluxes the heat transfer rate near the upstream end of the microchannels is higher than towards the downstream end. As a result, dryout would be initiated near the downstream end. At an input heat flux of $12 \mathrm{~W} / \mathrm{cm}^{2}$, the fluid temperature in the outlet manifold is measured to be $110^{\circ} \mathrm{C}$ (Fig. 7), a value that is significantly higher than the saturation temperature of FC-77 $\left(97^{\circ} \mathrm{C}\right)$ at atmospheric pressure, suggesting that dryout has occurred. When wall dryout occurs near the exit of the microchannels, a redistribution of heat in the channel wall is expected, with more heat being concentrated towards the upstream section of the heat sink, as noted in [15].

Heat transfer coefficients at different wall temperatures for the different flow rates are shown in Fig. 8 . It is seen that at low wall temperatures $\left(105\right.$ to $\left.110^{\circ} \mathrm{C}\right)$, higher heat transfer coefficients are obtained at the lower flow rate. This trend reverses with the heat transfer coefficient being highest for the highest flow rate as the wall temperature increases and the boiling process in the microchannels becomes well established. The plots include data up until CHF is reached. It is seen that the optimal heat transfer coefficient occurs before CHF is reached; the wall temperature at which this optimal heat transfer coefficient is noted appears to increase somewhat with flow rate.

\section{Comparison with Existing Correlations}

Table 3 lists selected boiling heat transfer correlations, against which the present results are compared. Conventional correlations for boiling in large channels are not included since they have previously been found not to apply to flow boiling in small channels $[1,2,5]$. Predictions from these correlations are included in Fig. 8.

Table 3. Boiling heat transfer correlations used for comparison with present experiments.

\begin{tabular}{l|l}
\hline Reference & Correlations \\
\hline Kandlikar [16] & $\begin{array}{l}h_{t p, N B D}=\left(0.6683 C o^{-0.2}+1058.0 B o^{0.7} F_{F l}\right) h_{s p}(1-x)^{0.8} \\
(11)\end{array}$ \\
\hline Cooper [17] & $h=55 P_{r}^{0.12}\left(-\log _{10} P_{r}\right)^{-0.55} M^{-0.5} q^{1 / 0.67}, P_{r}=P / P_{c}$ \\
\hline Rohsenow [18] & $q^{\prime \prime}=\mu_{l} h_{f g}\left[\frac{g\left(\rho_{l}-\rho_{v}\right)}{\sigma}\right]^{1 / 2}\left(\frac{C_{P}\left(T_{w}-T_{s a t}\right)}{C_{s f} h_{f g}}\right)^{0.33} \operatorname{Pr}_{l}^{-5.15}$ \\
\hline $\begin{array}{l}\text { Stephan and Abdelsalam [3] } \\
\text { for hydrocarbons }\end{array}$ & $q^{\prime \prime}=\left\{C_{2}\left[T_{w}-T_{s a t}\left(P_{l}\right)\right]\right\}^{1 / 0.33}$ \\
\hline Borishansky [19] & $q^{\prime \prime}=\left(A^{*}\right)^{3.33}\left[T_{w}-T_{s a t}\right]^{3.33}\left[F\left(P_{r l}\right)\right]^{3.33}$ \\
& $A^{*}=0.1011 P_{c}^{0.69}, P_{r}=P / P_{c}$ \\
\hline
\end{tabular}

Fig. 8 shows that predictions from the Cooper correlation best match the measured data, while the Rohsenow and Brishansky correlations significantly underpredict the measured heat transfer coefficients. Although the selected 
correlations are expected to predict nucleate boiling heat transfer in water, Collier and Thome [20] indicated that the Cooper correlation is the most universal in the group as it accounts for the liquid properties and molecular weights.

Since the boiling heat transfer in microchannels appears to be well predicted by nucleate boiling correlations, the two mechanisms have been thought to be somewhat analogous [1,21]. However, flow boiling in microchannels is characterized by certain unique characterisitcs such as flow instability and flow acceleration downstream in the microchannels that are still not well understood. The general applicability of the agreement with the Cooper correlation in Fig. 8 warrants further investigation. Also, as the wall temperature is increased, Fig. 8 shows that larger flow rates give rise to higher heat transfer coefficients. This may be attributed to the increased contribution to the overall heat transfer from convective boiling heat transfer, which depends on flow rate.

\section{Critical Heat Flux}

The measured CHF at the different flow rates were indicated in Fig. 5 and are given in Table 2. The CHF values from the present work are comparable to those obtained by Lazarek and Black [8] (from 10 to $33 \mathrm{~W} / \mathrm{cm}^{2}$ ) in a study of flow boiling heat transfer of R-113 in single microchannels of different lengths (from 12 to $26 \mathrm{~cm}$ ) for flow rates of 60 to $140 \mathrm{ml} / \mathrm{min}$.

The CHF value of over $200 \mathrm{~W} / \mathrm{cm}^{2}$ reported in Bowers and Mudawar [11] for a similar microchannel heat sink (with $\mathrm{R}-113$ as the coolant and flow rates of 15 to $90 \mathrm{ml} / \mathrm{min}$ ), included the enhancement due to a heat spreader present between the heat source and the microchannel heat sink; the heat source size was used to calculate the reported CHF value in that work. A more reasonable comparison with this result is obtained by comparing the heat transfer rates corresponding to $\operatorname{CHF}\left(q_{C H F}^{\prime \prime} \cdot A\right)$ from the two studies, as shown in Fig. 9.

It is seen in Fig. 9 that the heat transfer rate increases almost linearly with flow rate for both working fluids. It is also noted that the heat transfer rate obtained for R-113 is higher than that for FC-77 mainly due to the higher latent heat of the former (147 kJ/kg for R-113, $89 \mathrm{~kJ} / \mathrm{kg}$ for FC-77). The ratio of measured heat transfer rate at CHF to the limiting evaporation rate, $r_{c}=\left(q_{C H F}^{\prime \prime} A\right) /\left(\rho Q h_{f g}\right)$, is plotted in Fig. 10. This ratio is seen to decrease as the flow rate increases, asymptotically approaching unity. This implies that the contribution of convective heat transfer to the critical heat flux (relative to liquid evaporation) becomes less significant as flow rate increases.

Besides the limiting evaporation rate, $\rho_{l} Q h_{f g}$, other parameters that have been proposed to contribute to the critical heat flux [22] include $\Delta h_{i n} / h_{f g}, \rho_{v} / \rho_{l}, L / D_{h}$, and $\sigma \rho_{l} / G^{2} L$; that is, 


$$
\frac{q_{C H F}^{\prime \prime}}{G h_{f g}}=f\left(\frac{\Delta h_{i n}}{h_{f g}}, \frac{\rho_{v}}{\rho_{l}}, \frac{L}{D_{h}}, \frac{\sigma \rho_{l}}{G^{2} L}\right),
$$

in which $\Delta h_{i n} / h_{f g}$, related to the inlet subcooling, was stated to have a negligible effect on CHF [7, 11]. The density ratio, $\rho_{v} / \rho_{l}$, represents the density change during liquid evaporation; for smaller $\rho_{v} / \rho_{l}$, the same quantity of liquid produces a larger volume of vapor, leading to a greater tendency for wall dryout. The Weber number $\sigma \rho_{l} / G^{2} L$ is a ratio of surface tension to inertial force, and the CHF increases with this ratio as suggested in [22]. The critical heat flux should decrease with the length ratio, $L / D_{h}$ due to the larger conduction resistance in the wall for heat redistribution for larger $L / D_{h}$. For the same reason, the thermal conductivity of the channel wall should come into play because a smaller wall thermal conductivity would offer a larger thermal resistance for heat redistribution from the exit to the inlet. Therefore, the dimensionless parameter $k_{w} / k_{l}$ should also be included in equation 16 , and it is expected that the critical heat flux would increase with this ratio. A preliminary correlation of the form of equation 16 was provided based on the current results in [23]; however, for a more generalized CHF correlation, additional data would need to be obtained.

\section{SUMMARY AND CONCLUSIONS}

An experimental study of flow boiling heat transfer of the dielectric fluid FC-77 in a microchannel heat sink was conducted. Major findings from this work are summarized as follows:

1. As the boiling process becomes well established in the microchannels, a weak dependence of wall temperature on heat flux was measured, which is attributed to the flow oscillation at high heat fluxes.

2. Wall temperature measurements reveal that wall dryout first occurs near the exit of the microchannels.

3. The nucleation boiling correlation of Cooper [17] was found to agree very well with the measured heat transfer coefficients in this work.

4. The critical heat flux was found to increase with flow rate. The ratio of heat transfer rate at CHF to the limiting evaporation rate, $\left(q_{C H F}^{\prime \prime} A\right) /\left(\rho Q h_{f g}\right)$, decreases with increasing flow rate, and asymptotically approaches unity as flow rate increases.

5. The dimensionless parameters affecting CHF were analyzed, and it is suggested that the wall thermal conductivity be included among the governing parameters. 


\section{ACKNOWLEDGEMENT}

Support for this work from the Indiana $21^{\text {st }}$ Century Research and Technology Fund is gratefully acknowledged.

\section{REFERENCES}

[1] P. A. Kew and K. Cornwell, "Correlations for the prediction of boiling heat transfer in small-diameter channels," Applied Thermal Engineering, vol. 17, pp. 705-715, 1997.

[2] T. N. Tran, M.W. Wambsganss, and D.M. France., "Small circular and rectangular channel boiling with two refrigerants," International Journal of Multiphase Flow, vol. 22, pp. 485-498, 1996.

[3] K. Stephan and M. Abdelsalam, "Heat transfer correlation for natural convection boiling," International Journal of Heat and Mass Transfer, vol. 23, pp. 73-87, 1980.

[4] R. Mertz, A. Wien, and M. Groll, "Experimental investigation of flow boiling heat transfer in narrow channels," Heat and Technology, vol. 14, pp. 47-54, 1996.

[5] W. Qu and I. Mudawar, "Transport phenomena in two-phase microchannel heat sinks," Journal of Electronic Packaging, vol. 126, pp. 213-224, 2004.

[6] D. D. Hall and I. Mudawar, "Critical heat flux for water in tubes - I. Compilation and assessment of world CHF data," International Journal of Heat and Mass Transfer, vol. 43, pp. 2573-2604, 2000.

[7] C. L. Vandervort, A. E. Bergles, and M. K. Jensen, “An experimental study of critical heat flux in very high heat flux subcooled boiling," International Journal Heat and Mass Transfer, vol. 37, supplement 1, pp. 161-173, 1994.

[8] G. M. Lazarek and S. H. Black, "Evaporative heat transfer, pressure drop and critical heat flux in a small vertical tube with R113," International Journal of Heat and Mass Transfer, vol. 25, pp. 945-960, 1982.

[9] W. Yu, D. M. France, M. W. Wambsganss, and J. R. Hull, “Two-phase pressure drop, boiling heat transfer, and critical heat flux to water in a small-diameter horizontal tubes," International Journal of Multiphase Flow, vol. 28, pp. 927-941, 2004.

[10] L. S. Tong, "Boiling crisis and critical heat flux", US Atomic Energy Commission.

[11] M. B. Bowers and I. Mudawar, "High flux boiling in low flow rate, low pressure drop mini-channel and micro-channel heat sinks," International Journal of Heat and Mass Transfer, vol. 37, pp. 321-332, 1994.

[12] T. Chen and S. V. Garimella, "Effects of dissolved air on subcooled flow boiling of a dielectric coolant in a microchannel heat sink," ASME Journal of Electronic Packaging, in press.

[13] S. J. Kline and F. A. McClintock, "Describing uncertainties in single-sample experiments," Mechanical Engineering, vol. 75, pp. 3-8, 1953.

[14] R. K. Shah and A. L. London, "Laminar flow forced convection in ducts," Supplement 1 to Advances in Heat Transfer, Academic Press, New York, 1978. 
[15] A. E. Bergles and S. G. Kandlikar, "Critical heat flux in microchannels: experimental issues and guidelines for measurement," in Proceedings of $1^{\text {st }}$ International Conference on Microchannels and Minichannels, Rochester, New York, 2003.

[16] S. G. Kandlikar, "A general correlation for saturated two-phase flow boiling heat transfer inside horizontal and vertical tubes," Journal of Heat Transfer, vol. 112, pp. 219-228, 1990.

[17] M. G. Cooper, "Saturated nucleate pool boiling - a simple correlation," in $1^{\text {st }}$ UK National Heat Transfer Conference IChemE Symp. Series No. 86, vol. 2, pp. 785-793, 1984.

[18] W. M. Rohsenow, “A method of correlating heat transfer data for surface boiling of liquids," Transactions of ASME, vol. 74, pp. 969-976, 1962.

[19] V. P. Carey, Liquid-vapor Phase-Change Phenomena, Taylor and Francis, 1992.

[20] J. G. Collier and J. R. Thome, Convective Boiling and Condensation, $3^{\text {rd }}$ ed., Oxford University Press, 1994.

[21] M. R. Aligoodarz and D. B. R. Kenning, "Vapor bubble behavior in a single narrow channel," In Proceedings of $4^{\text {th }}$ UK National Conference on Heat Transfer, Manchester, UK, pp. 273-276, I. Mech. E., 1995.

[22] Y. Katto, "A generalized correlation of critical heat flux for the forced convection boiling in vertical uniformly heated round tubes," International Journal of Heat and Mass Transfer, vol. 21, pp. 1527-1542, 1978

[23] T. Chen and S.V. Garimella, "Flow boiling heat transfer of a dielectric coolant in a microchannel heat sink," Proceedings of InterPACK '05, San Francisco, California, July 17-22, 2005. 


\section{LIST OF FIGURE CAPTIONS}

Fig. 1. Experimental test loop.

Fig. 2. Schematic of the expandable reservoir used to degas the liquid.

Fig. 3. Details of the (a) microchannel heat sink and (b) heat sink test section used in the experiments.

Fig. 4. Comparison of single phase heat transfer coefficients against predictions from laminar flow heat transfer correlation.

Fig. 5. Wall temperature at different heat fluxes.

Fig. 6. Identification of CHF from measured wall temperature variation with time (CHF is $21.3 \mathrm{~W} / \mathrm{cm}^{2}$ at this flow rate).

Fig. 7. Temperature measurements at different heat fluxes.

Fig. 8. Heat transfer coefficients at different wall temperatures for the three flow rates.

Fig. 9. The critical power at CHF from present work and from Bowers and Mudawar [11].

Fig. 10. Ratio of heat transfer rate at CHF to the limiting evaporation rate at different flow rates.

\section{LIST OF TABLE CAPTIONS}

Table 1. Approximate heat fluxes and wall temperatures for bubble incipience.

Table 2. Critical heat fluxes at three flow rates.

Table 3. Boiling heat transfer correlations used for comparison with present experiments. 


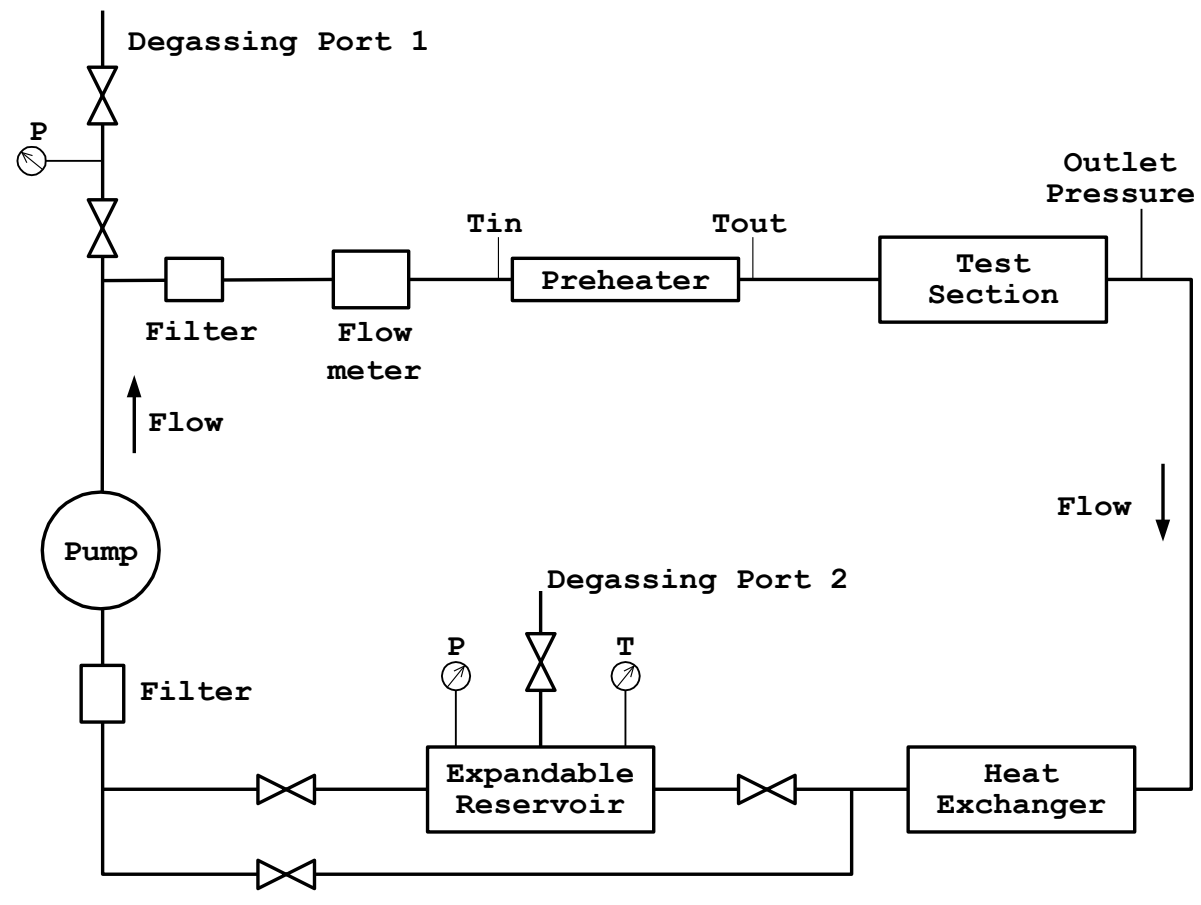

Fig. 1. Experimental test loop. 


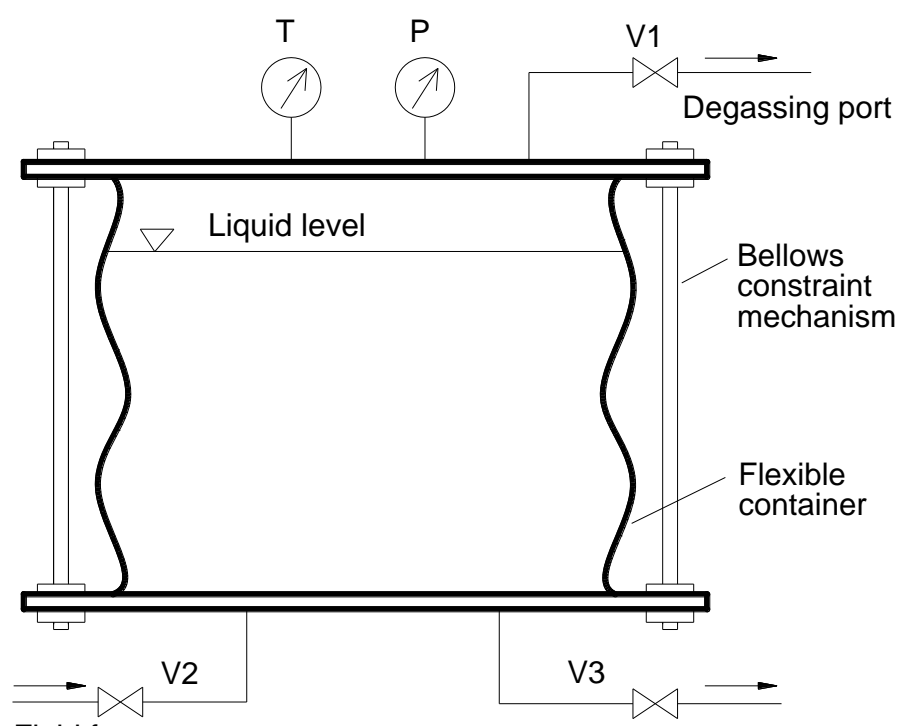

Fluid from system

Fluid into the system

Fig. 2. Schematic of the expandable reservoir used to degas the liquid. 


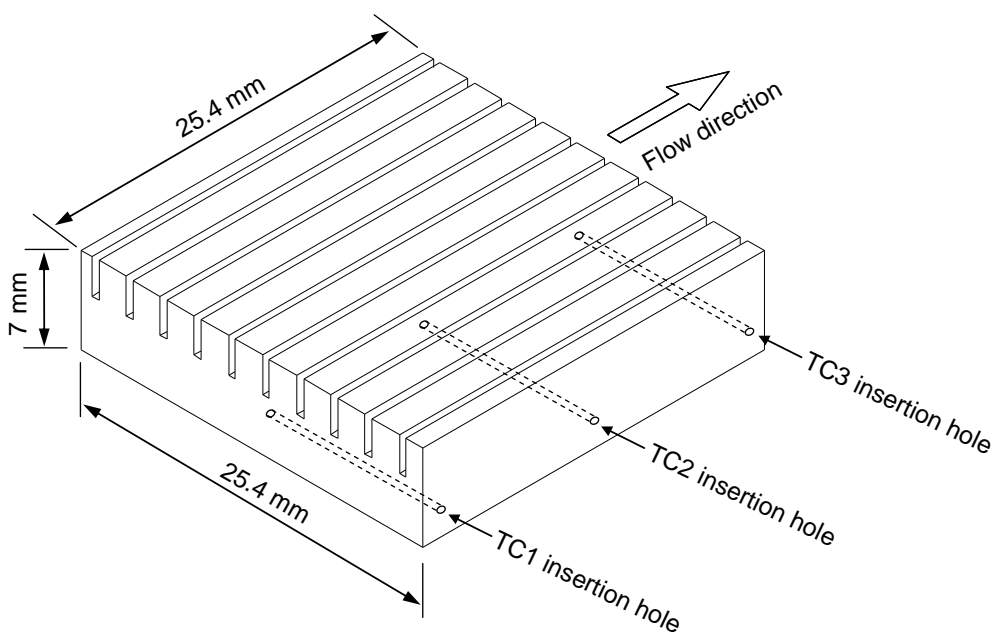

(a)

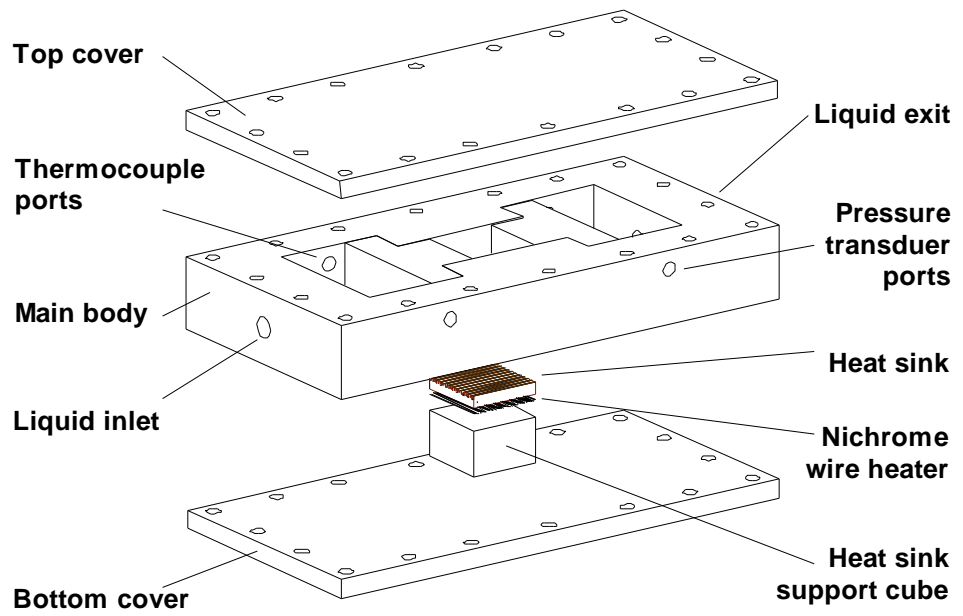

(b)

Fig. 3. Details of the (a) microchannel heat sink and (b) heat sink test section used in the experiments. 


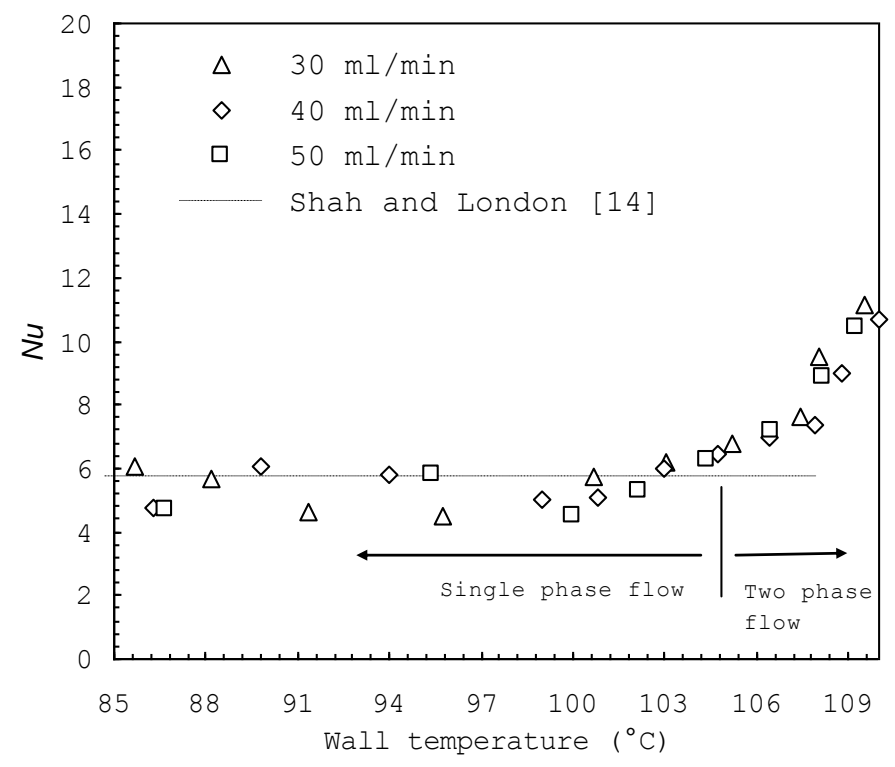

Fig. 4. Comparison of single phase heat transfer coefficients against predictions from laminar flow heat transfer correlation. 


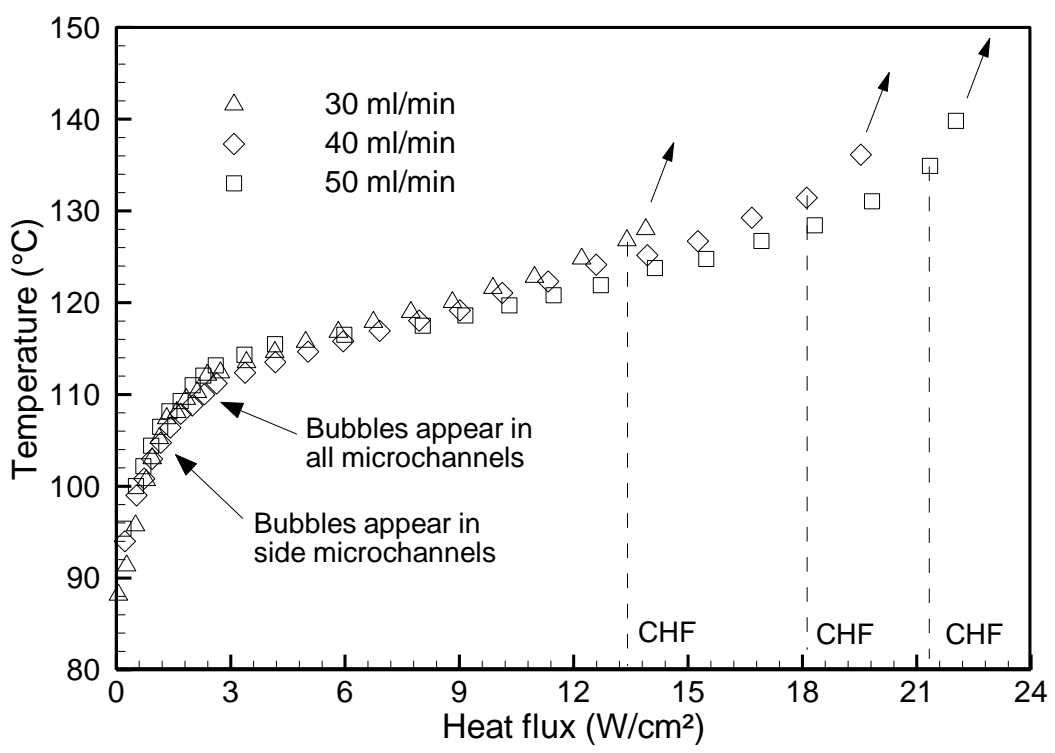

Fig. 5. Wall temperature at different heat fluxes. 


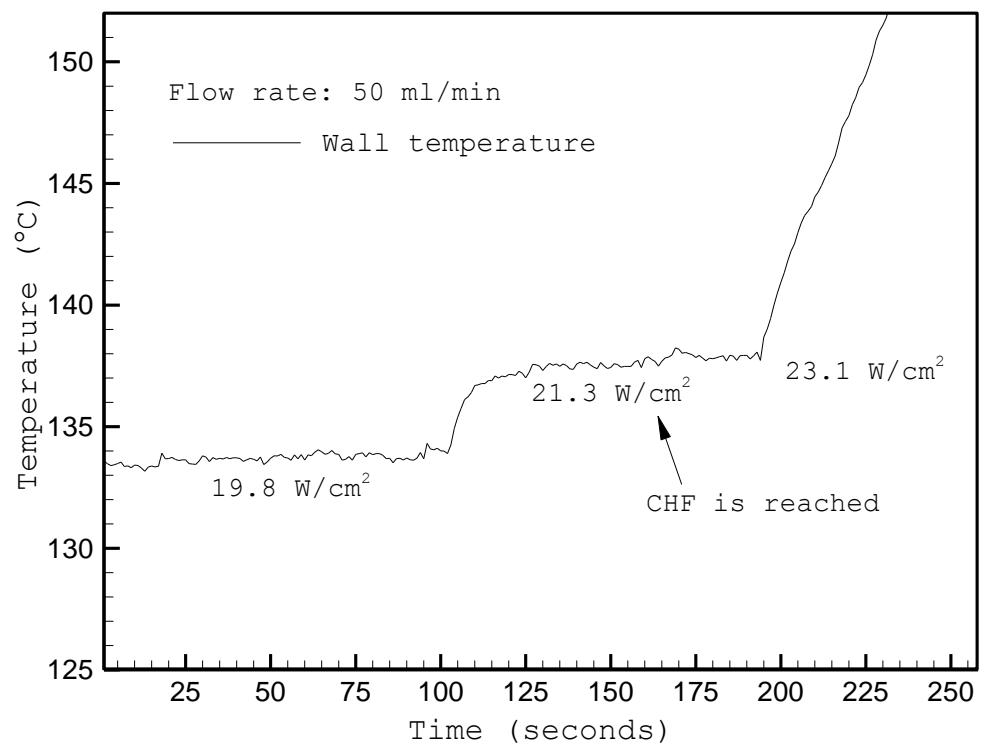

Fig. 6. Identification of $\mathrm{CHF}$ from measured wall temperature variation with time (CHF is $21.3 \mathrm{~W} / \mathrm{cm}^{2}$ at this flow rate). 


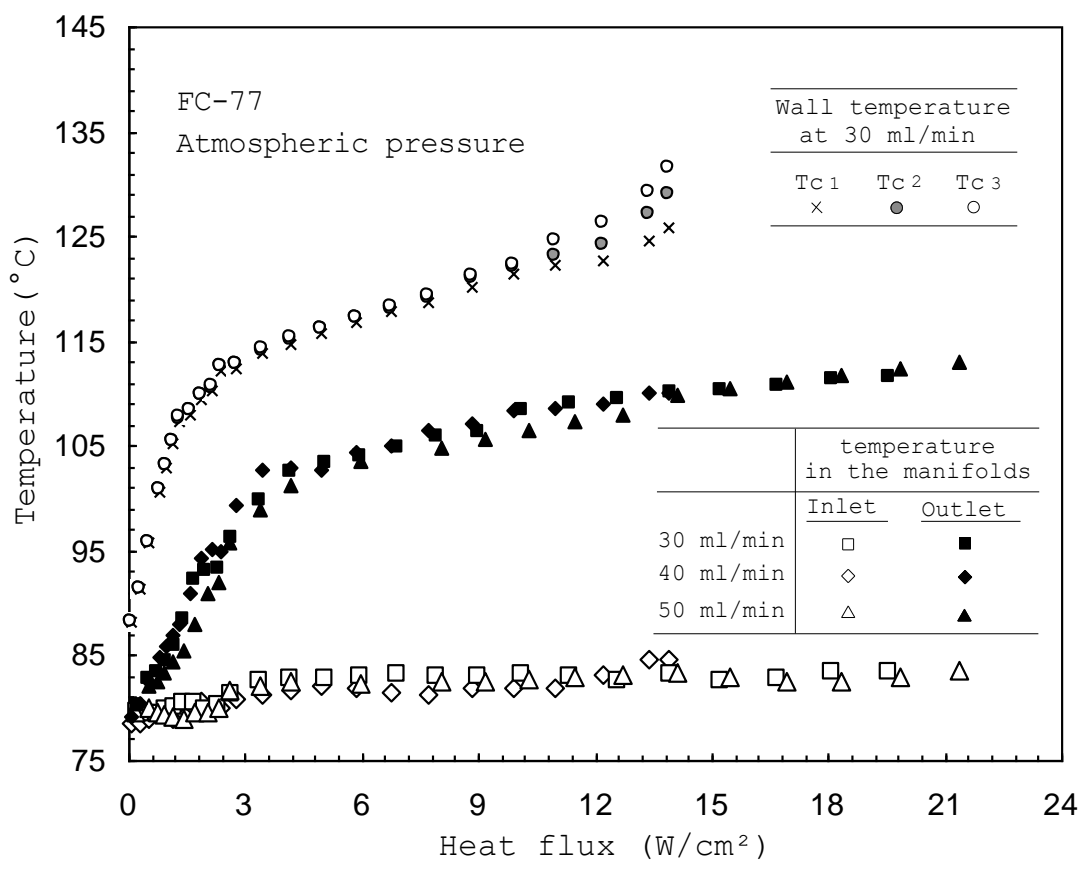

Fig. 7. Temperature measurements at different heat fluxes. 


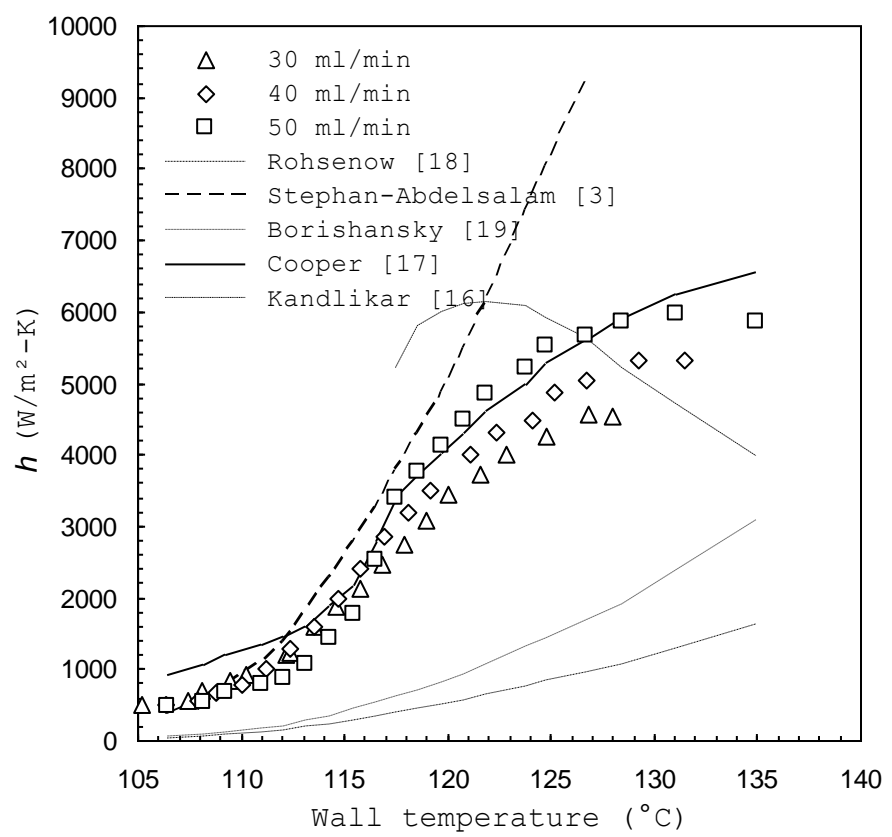

Fig. 8. Heat transfer coefficients at different wall temperatures for the three flow rates. 


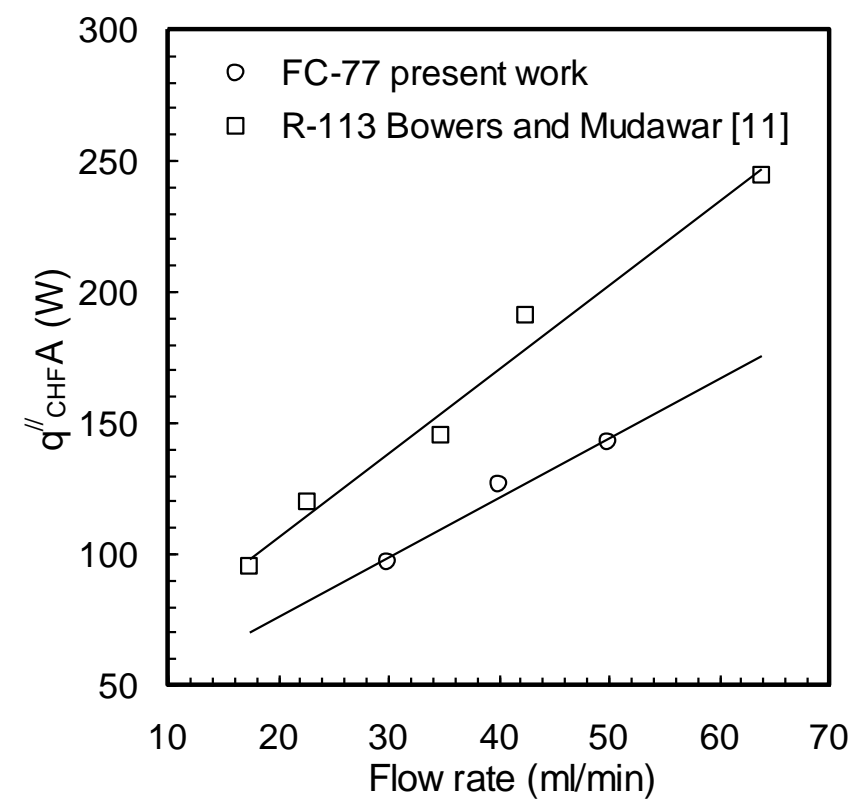

Fig. 9. The critical power at CHF from present work and from Bowers and Mudawar [11]. 


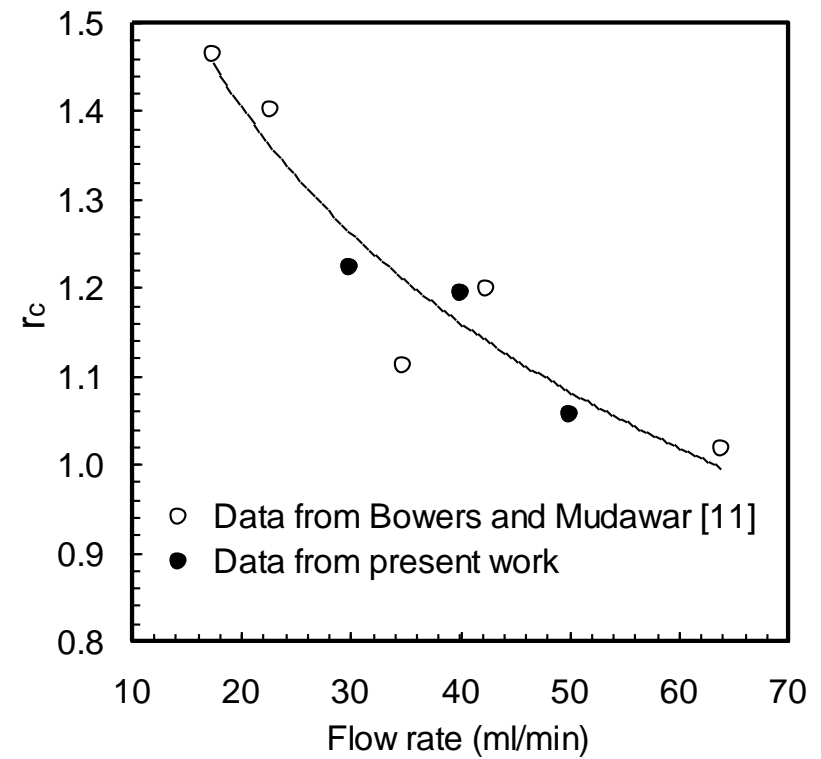

Fig. 10. Ratio of heat transfer rate at CHF to the limiting evaporation rate at different flow rates. 